\title{
Metamizol and Scopolamine for Conventional or Two-Port Laparoscopic-Assisted Ovariohysterectomy in Dogs*
}

\author{
Fabíola Dalmolin ${ }^{1,2}$, Marília Teresa Oliveira ${ }^{3}$, Saulo Tadeu Lemos Pinto Filho², \\ Marcos André Braz Vaz ${ }^{4}$, Bianca Bertoletti ${ }^{2}$, Virgínia Heinz Pohl' ${ }^{5}$, \\ João Pedro Scussel Feranti ${ }^{2}$, Hellen Fialho Hartmannn ${ }^{2}$ \& Maurício Veloso Brun ${ }^{2}$
}

\begin{abstract}
Background: Ovariohysterectomy (OVH) is one of the most applied techniques in Veterinary Medicine. Despite some analgesic protocols being used after this procedure in order to control post operatory pain, there is a lack of knowledge of the efficacy after conventional and two port laparoscopic-assisted techniques in dog female. Although the combined formulation of metamizol and scopolamine is used, there is no knowledge about the efficacy and collateral effects in a $6 \mathrm{~h}$ regimen after $\mathrm{OVH}$. The aim of this research was to evaluate the efficacy of metamizol and scopolamine to analgesia after two techniques of $\mathrm{OVH}$ in dog female.

Materials, Methods \& Results: Fifteen adults and healthy dog female were submitted to OVH, being eight to the conventional procedure and seven to video assisted technic with two ports. The patients received a combination of metamizol and scopolamine, 6-6 h during $48 \mathrm{~h}$ and were evaluated before surgery, $60 \mathrm{~min}$ after extubation and on $1 \mathrm{~h}$ interval during the first $8 \mathrm{~h}$, and at 12, 18, 24, 36, 48 and $72 \mathrm{~h}$ after surgery. For this, the University of Melbourne Pain Scale (UMPS) and the short-form of the Glasgow Composite Measure Pain Scale (CMPS-SF) were applied by three evaluators blinded to surgical technic. Glucoses measurement was realized at 1, 6, 12, 24, 48 and $72 \mathrm{~h}$ after surgery. Analgesic rescue was not necessary for any animal. Punctuation of UMPS in GC decreases at $8 \mathrm{~h}$ and at $5 \mathrm{~h}$, and to GV at 12 and $24 \mathrm{~h}$. Difference between groups happened at $3 \mathrm{~h}$ with larger average to $\mathrm{GV}$; at $48 \mathrm{~h}$ the punctuation in $\mathrm{GC}$ was lager. Considering CMPS-SF to CG, higher average was observed at $1 \mathrm{~h}$ and decreased at 2, 3,8 and 18. At GV highest average points was verified at 1, 2 and 3 $\mathrm{h}$ and decreased at 5,8 and $18 \mathrm{~h}$. Correlation was strong and positive between each two evaluators. Animals of both groups had increased average glucose concentrations from baseline to after surgery and the values reduced to baseline after 24 $\mathrm{h}$; difference between groups were observed at $1 \mathrm{~h}$ after surgery, with bigger average to GC. Three animals from the GC had postoperative emesis and one patient vomited after $3 \mathrm{~h}$; other at $6 \mathrm{~h}$ and another at 36 and $48 \mathrm{~h}$ and owners related no vomiting or changes following hospital discharge. The time to first spontaneous food intake was earlier to GV and time to first defecation was no different between groups.

Discussion: For the evaluation it was used the UMPS and CMPS-SF since it is know that pain assessment is better performed when multidimensional or composite scales are used. Considering the UMPS, 27 points is considered the most painful condition. In our study it was observed bigger average to $\mathrm{GC}$ at $1 \mathrm{~h}(4,5)$ and to GV at 2 and $3 \mathrm{~h}(5,0)$. According to CMPS-SF, higher punctuation to GC $(7.0)$ was observed than GV $(6,0)$ in a maximum of 24 points. Considering both scales, it could be suggested that the combination of metamizol and scopolamine promote good analgesic effect. The glucoses measurements and the first spontaneous food intake suggested that laparoscopic approaches results in less stress than the traditional procedures, as observed in other studies. Three animals of GC had postoperative emesis, and it signal can be associated to abdominal pain, as well nausea, vomiting, diarrhea and abdominal distention, probably because it is accepted that video surgery promotes less pain and stress than open procedures. The protocol was efficient to control pain after elective conventional and laparoscopic assisted OHV technique in dog female.
\end{abstract}

Keywords: analgesic protocol, Glasgow Scale, Melbourne Scale, pain control, surgery.

*Article based on a Dissertation submitted by the senior author in partial fulfillment of requirements for the Doctor's Degree (PPGMV-UFSM). ${ }^{1}$ Programa de Pós-Graduação em Saúde, Bem-estar e Produção Animal Sustentável Universidade Federal da Fronteira Sul (UFFS), Realeza, PR, Brazil. ${ }^{2}$ Programa de Pós-Graduação em Medicina Veterinária Veterinária (PPGMV), Universidade Federal de Santa Maria (UFSM), Santa Maria, RS, Brazil. ${ }^{3}$ Universidade Federal do Pampa (UNIPAMPA), Campus Uruguaiana, RS. ${ }^{4}$ Universidade Federal do Amazonas (UFMA), Manaus, AM, Brazil. ${ }^{5}$ Autonomous Veterinary, Santa Maria. CORRESPONDENCE: F. Dalmolin [fabiola.dalmolin@uffs.edu.br]. Serviço de Clínica Cirúrgica Animal, Unidade Hospitalar Veterinária - UFFS Campus Realeza. Av. Edmundo Gaievski n. 1000. CEP 85770-000 Realeza, PR, Brazil. 


\section{INTRODUCTION}

The International Association for the study of Pain defined pain as "an unpleasant sensory and emotional experience associated with actual or potential tissue damage or described in terms of such damage". Pain delays healing, suppresses the immune system and increases blood viscosity as well as normal behaviors and can precipitate abnormal behaviors as self-trauma, hiding and aggression [21].

Metamizol, or dipyrone, is a weak non-steroidal anti-inflammatory drug with powerful pain-relieving, antipyretic and spasmolytic properties [14] used in some countries in order to control post operatory pain, among others [6]. The mechanism of action seems to be related COX-3 enzymes inhibition, which could represent a primary central mechanism that decreases pain and possibly fever [2].

$\mathrm{N}$-butylscopolamine bromide treat pain from colic in humans, because it acts in smooth abdominal and pelvic muscles by affect the intramural parasympathetic ganglion of smooth abdominal and pelvic muscle [9]. There is a lack of information about the use of metamizol and scopolamine combination in dogs, although in Brazilian routine, the commercial combination of these drugs is used in veterinary routine in order to control post operatory pain.

Laparoscopic-assisted interventions are gaining popularity in veterinary medicine [15], in part because of the realized and potential reduction in tissue trauma when compared with laparotomy [8]. A decrease in inflammatory mediators (e.g., C-reactive protein, interleukin-6), cells (e.g., white blood cells) and metabolic responses suggestive of stress (e.g., hyperglycemia) in patients undergoing laparoscopic versus open surgical intervention are taken as support of this. In animal study, albeit limited, evidence from animal studied supports that as for human patients, there is less pain associated with a laparoscopic versus a traditional surgical approach [15].

Compared to the conventional procedure, video laparoscopic surgery presents some advantages as lower incisions, what reduce post operatory pain, morbidity and promote fast recovering [5]. Pain is an inevitable consequence of surgery [7], but theoretically compared to the conventional, pain after laparoscopic surgery is considered less intense and shorter time duration. Despite this information, in both cases, the adequate control of pain is necessary and promote fast recovery [12].

Although studies have compared pain in dog female undergone conventional or laparoscopic ovar- iohysterectomy $(\mathrm{OVH})$ in bitches, literature regarding to the efficacy of metamizol and scopolamine to adequately treat pain after these surgery is sparse. The purpose of this study was to compare the analgesic efficacy of metamizol and scopolamine after conventional and two-port laparoscopic-assisted in bitches.

\section{MATERIALS AND METHODS}

\section{Animals}

Fifteen healthy young adult bitches, of different breeds, 1 to 4 years, $14.9 \pm 2.87 \mathrm{~kg}$ were included. In order to verify health condition, clinical examination and laboratorial assessment (complete blood count, serum creatinine, albumin, alkaline phosphatase and alanine aminotransferase) were performed. Animals were hospitalized $48 \mathrm{~h}$ previously to the surgery and immediately received orally nitenpyram ${ }^{1}\left(1 \mathrm{mg} \cdot \mathrm{kg}^{-1}\right)$, as well as water and commercial food ad libitum, and remained on acclimatized environment $\left(22^{\circ} \mathrm{C}\right)$. Patients contacted just researchers and animals involved in the study during the evaluation period.

\section{Anesthetic and surgical procedure}

After $12 \mathrm{~h}$ fasting for food and $8 \mathrm{~h}$ for water, a general physical examination was performed and heart and respiratory rates, systolic arterial pressure and rectal temperature were evaluated. A broad trichotomy of the abdomen was accomplished and dogs were allocated randomly in two groups, celiotomy (GC) and two-port laparoscopic-assisted (GV).

Animals received acepromazine ${ }^{2}\left(0.05 \mathrm{mg} . \mathrm{kg}^{-1}\right.$ i.m.) and $10 \mathrm{~min}$ later a venous access was performed and Ringer's lactate solution $\left(10 \mathrm{~mL} \cdot \mathrm{kg}^{-1} \cdot \mathrm{h}^{-1}\right.$ i.v. $)$ instituted. The anesthesia was induced with propofol ${ }^{3}$ (4 mg.kg-1 i.v.) followed of tracheal intubation and isoflurane vaporized in $100 \%$ oxygen, adjusted to keep the patients on adequate anesthetic plane (palpebral reflexes absent, corneal reflex present, and rotated eyeball), in spontaneous breathing system. A loading dose of fentanyl ${ }^{4}$ was administrated $\left(1.25 \mu \mathrm{g} . \mathrm{kg}^{-1}\right.$, i.v. over five min), followed by a constant rate infusion of 15 $\mu \mathrm{g} \cdot \mathrm{kg}^{-1} \cdot \mathrm{h}^{-1}$ through a peristaltic infusion pump. Sodium ampicillin (20 mg. $\mathrm{kg}^{-1}$, i.v.) was used to prophylaxis.

A single surgeon proficient on the techniques performed all surgeries. A standard retro-umbilical celiotomy comprising one-third of the distance between the umbilicus and the pubis was performed to conventional OVH (GC; $n=8)$. After manual rupture of the ovarian suspensory ligament, the modified three-clamp 
technique and double ligatures with 2-0 polyglactin 910 were used to hemostasis of the ovarian pedicles and uterine body vessels [16]. To VG group, two 10 $\mathrm{mm}$ port was inserted through the umbilicus and in the pre-pubic area $(n=7)$ [1]. To hemostasis and transection of the ovarian pedicles and suspensory ligament bipolar cauterization ${ }^{5}$ was used; double ligatures and the same material were applied on the uterine body. To the abdominal wall Sultan pattern as used, and to the subcutaneous zig zag, both with poliglactina 910 . To dermorraphy we used nylon 2-0 and Wolf pattern.

Surgical time was measured in minutes. Immediately after the end of the procedures, patients received intravenously a commercial combination of metamizol (25 mg. $\left.\mathrm{kg}^{-1}\right)$ and scopolamine ${ }^{6}\left(0.2 \mathrm{mg} \cdot \mathrm{kg}^{-1}\right)$; following doses were applied 6-6 h during $48 \mathrm{~h}$ subcutaneous.

Pain Assessment

Three trained evaluators blinded to surgical technique and analgesic protocol performed the assessment. The abdomen was completely covered and the ventral region protected by sterile surgical compress, bandages and elastic sheath. Previously to the assessments, a research checked if the dressings were in place and changed it when required. Pain assessment began $60 \mathrm{~min}$ after extubation and was conducted on $1 \mathrm{~h}$ intervals during the first $8 \mathrm{~h}$, and at 12, 18, 24, 36, 48 and $72 \mathrm{~h}$ after surgery.

The University of Melbourne Pain Scale (UMPS) and the short-form of the Glasgow Composite Measure Pain Scale (CMPS-SF) were utilized. Each evaluator performed an individual assessment and all realized it at the same time, without influence of the others. The evaluation started after opening the box, followed by observation of the patient exiting and gentle palpation of the ventral abdominal area. Rescue analgesia using morphine sulphate $\left(0.5 \mathrm{mg} \cdot \mathrm{kg}^{-1}, \mathrm{i} . \mathrm{m}\right.$. $)$ would be used if punctuation of $30 \%$ of the maximum scales scores was achieved. Glucoses were measured immediately before surgery and at 1, 6, 12, 24, 48 and $72 \mathrm{~h}$. Food intake and time for the first defecation was observed.

\section{Statistical analysis}

Pain assessment, glucoses measurement, time to first spontaneous food intake and defecation were compared using Kruskal-Wallis test within group, among moments, or, Mann-Whitney between groups, in each moment. In order to compare median and the correlation, the Scott-Knott test and Sperman test were used, respectively. Agreement among evaluators was tested by Kappa coefficient and the correlation classified by Santos [20]. The level of significance was 5\% and the analysis was performed using a software [19].

\section{RESULTS}

Body weight was similar for dogs into groups, being $15.01 \pm 2.45 \mathrm{~kg}$ to $\mathrm{CG}$ and $14.8 \pm 3.36 \mathrm{~kg}$ to $\mathrm{GV}$. The procedures were realized in a randomized manner. There were no significant operative intercurrences in any patient, as well as evidence of hemorrhage or iatrogenic trauma during or after surgeries. Mean surgery time was significantly longer for video assisted (31.3 min) compared to open surgery $(19.0 \mathrm{~min})[P<0.01]$. All animals recovered from anesthesia and no alteration was related.

Table 1 and Figure 1 shows, respectively, the values and the boxplots of median, first and third quartiles of the total points average of pain evaluation using UMPS and CMPS-SF scales. Data are presented according to the pain evaluation scale and time after surgery. Considering scales punctuation, analgesic rescue was not necessary, demonstrating the efficiency of the analgesic protocol after both surgical technics.

According to the UMPS was observed decreasing of average to $\mathrm{GC}$ at $8 \mathrm{~h}$; at $\mathrm{GV}$ decreasing of average were observed at 5, 12 and $24 \mathrm{~h}$. At $36 \mathrm{~h}$ the average increased, and after $48 \mathrm{~h}$ decreased. Difference between groups was observed at $3 \mathrm{~h}$ and larger average was present in GV (5.0) than GC (4.0); at $48 \mathrm{~h}$ was observed bigger punctuation in GC (3.0) than GV (2.0). Considering the CMPS-SF to the $\mathrm{CG}$, higher punctuation was observed at $1 \mathrm{~h}(7.0)$ and decreased at 2, 3, 8 and finally $18 \mathrm{~h}$. At GV was observed highest average at 1, 2 and $3 \mathrm{~h}(6.0)$ and decreases at 5, 8 and $18 \mathrm{~h}$. No difference between groups happened. Considering both scales, the correlation was strong and positive between each two evaluators ( $r=0.88,0.89$ and 0.84 respectively).

Animals of GC and GV had increased glucose measurement after surgery. Values returned to baseline at $24 \mathrm{~h}$. Difference between groups were observed $1 \mathrm{~h}$ after surgery (GC: $P=0.00 ; \mathrm{GV}: P=0.04)$ and bigger average to $\mathrm{GC}(P=0.02)$ was observed (Figure 1).

Three animals from the GC had postoperative emesis. One patient vomited after $3 \mathrm{~h}$; other at $6 \mathrm{~h}$; and another at 36 and $48 \mathrm{~h}$. Owners related no vomiting or changes following hospital discharge. The time to first spontaneous food intake was earlier in the $\mathrm{GV}(\mathrm{GV}=$ $5.57 \pm 3.21 \mathrm{~h}, \mathrm{GC}=16.75 \pm 10.79 \mathrm{~h} ; P=0.02)$ and the time to first defecation was no different between groups $(\mathrm{GV}=17.60 \pm 9.21 \mathrm{~h}, \mathrm{GC}=31.71 \pm 17.90 \mathrm{~h}, P=0.11)$. 
F. Dalmolin, M.T. Oliveira, S.T.L. Pinto Filho, et al. 2020. Metamizol and Scopolamine for Conventional or Two-Port LaparoscopicAssisted Ovariohysterectomy in Dogs.

Acta Scientiae Veterinariae. 48: 1741.

Table 1. Median, first and third quartiles of the total points average of bitches underwent to two-port laparoscopic-assisted (GV) or conventional (GC) OVH, in different time points, using the University of Melbourne (UMPS) and the Short-Form of the Glasgow Composite Measure (CMPS-SF) pain scales. "b" and "d" indicates the baseline values in UMPS and CMPS-SF, respectively.

\begin{tabular}{|c|c|c|c|c|c|c|c|}
\hline \multicolumn{8}{|c|}{ UMPS } \\
\hline \multirow{2}{*}{ Time } & \multicolumn{3}{|c|}{ GC } & \multicolumn{3}{|c|}{ GV } & \multirow{2}{*}{$P$-value } \\
\hline & $\mathrm{Q}_{1}$ & Median & $\mathrm{Q}_{3}$ & $\mathrm{Q}_{1}$ & Median & $\mathrm{Q}_{3}$ & \\
\hline 1 & 3.0 & $4.5 \mathrm{a}$ & 6.2 & 3.0 & $4.0 \mathrm{~b}$ & 5.0 & $P=0.65$ \\
\hline 2 & 3.0 & $4.0 \mathrm{a}$ & 5.2 & 4.0 & $5.0 \mathrm{a}$ & 6.0 & $P=0.17$ \\
\hline 3 & 3.0 & $4.0 \mathrm{a}$ & 5.0 & 4.0 & $5.0 \mathrm{a}$ & 7.0 & $P=0.01$ \\
\hline 4 & 2.0 & $4.0 \mathrm{a}$ & 5.0 & 3.0 & $4.0 \mathrm{a}$ & 6.0 & $P=0.15$ \\
\hline 5 & 2.7 & $3.0 \mathrm{a}$ & 4.2 & 3.0 & $3.0 \mathrm{~b}$ & 6.0 & $P=0.28$ \\
\hline 6 & 3.0 & $4.0 \mathrm{a}$ & 5.2 & 3.0 & $3.0 \mathrm{~b}$ & 4.0 & $P=0.52$ \\
\hline 7 & 3.0 & $4.0 \mathrm{a}$ & 4.0 & 3.0 & $3.0 \mathrm{~b}$ & 5.0 & $P=0.81$ \\
\hline 8 & 2.0 & $3.0 \mathrm{~b}$ & 4.0 & 3.0 & $3.0 \mathrm{~b}$ & 4.0 & $P=0.38$ \\
\hline 12 & 2.0 & $3.0 \mathrm{~b}$ & 4.0 & 3.0 & $3.0 \mathrm{c}$ & 4.0 & $P=0.63$ \\
\hline 18 & 2.0 & $3.0 \mathrm{~b}$ & 4.0 & 2.0 & $3.0 \mathrm{c}$ & 3.0 & $P=0.96$ \\
\hline 24 & 2.0 & $2.5 \mathrm{~b}$ & 3.2 & 2.0 & $2.0 \mathrm{~d}$ & 2.0 & $P=0.09$ \\
\hline 36 & 2.0 & $3.0 \mathrm{~b}$ & 4.0 & 2.0 & $3.0 \mathrm{c}$ & 3.0 & $P=0.57$ \\
\hline 48 & 2.0 & $3.0 \mathrm{~b}$ & 3.0 & 1.0 & $2.0 \mathrm{~d}$ & 2.0 & $P=0.01$ \\
\hline 72 & 2.0 & $2.0 \mathrm{~b}$ & 3.0 & 1.0 & $2.0 \mathrm{~d}$ & 3.0 & $P=0.29$ \\
\hline$P$-value & & $P<0.01$ & & & $P<0.01$ & & \\
\hline \multirow{3}{*}{ Time } & \multicolumn{6}{|c|}{ CMPS-SF } & \multirow{3}{*}{$P$-value } \\
\hline & \multicolumn{3}{|c|}{ GC } & \multicolumn{3}{|c|}{ GV } & \\
\hline & $\mathrm{Q}_{1}$ & Median & $\mathrm{Q}_{3}$ & $\mathrm{Q}_{1}$ & Median & $\mathrm{Q}_{3}$ & \\
\hline 1 & 3.7 & $7.0 \mathrm{a}$ & 9,0 & 4.0 & $6.0 \mathrm{a}$ & 9,0 & $P=0.91$ \\
\hline 2 & 3.0 & $4.0 \mathrm{~b}$ & 8,0 & 3.0 & $6.0 \mathrm{a}$ & 8,0 & $P=0.48$ \\
\hline 3 & 1.0 & $4.0 \mathrm{c}$ & 8,0 & 3.0 & $6.0 \mathrm{a}$ & 8,0 & $P=0.23$ \\
\hline 4 & 1.7 & $3.5 \mathrm{c}$ & 6.0 & 3.0 & $5.0 \mathrm{a}$ & 8,0 & $P=0.14$ \\
\hline 5 & 2.0 & $4.0 \mathrm{c}$ & 6.0 & 2.0 & $4.0 \mathrm{~b}$ & 8,0 & $P=0.69$ \\
\hline 6 & 1.7 & $2.5 \mathrm{c}$ & 4.2 & 2.0 & $3.0 \mathrm{~b}$ & 8,0 & $P=0.31$ \\
\hline 7 & 2.0 & $2.0 \mathrm{c}$ & 3.0 & 2.0 & $3.0 \mathrm{~b}$ & 6.0 & $P=0.56$ \\
\hline 8 & 1.0 & $2.0 \mathrm{~d}$ & 3.0 & 2.0 & $2.0 \mathrm{c}$ & 3.0 & $P=0.31$ \\
\hline 12 & 1.0 & $2.0 \mathrm{~d}$ & 2.2 & 1.0 & $2.0 \mathrm{c}$ & 3.0 & $P=0.82$ \\
\hline 18 & 0.0 & $1.0 \mathrm{e}$ & 1.2 & 0.0 & $1.0 \mathrm{~d}$ & 2.0 & $P=0.32$ \\
\hline 24 & 0.0 & $0.0 \mathrm{e}$ & 1.0 & 0.0 & $0.0 \mathrm{~d}$ & 1.0 & $P=0.90$ \\
\hline 36 & 0.0 & $0.0 \mathrm{e}$ & 0.0 & 0.0 & $0.0 \mathrm{~d}$ & 1.0 & $P=0.19$ \\
\hline 48 & 0.0 & $0.0 \mathrm{e}$ & 0.0 & 0.0 & $0.0 \mathrm{~d}$ & 0.0 & $P=1.00$ \\
\hline 72 & 0.0 & $0.0 \mathrm{e}$ & 0.0 & 0.0 & $0.0 \mathrm{~d}$ & 0.0 & $P=0.92$ \\
\hline$P$-value & & $P<0.01$ & & & $P<0.01$ & & \\
\hline
\end{tabular}


Table 2. Median of glucoses at different evaluation times of bitches underwent to two-port laparoscopic-assisted (GV) or conventional (GC) OVH. "b" indicates the baseline values in UMPS and CMPS-SF.

\begin{tabular}{cccc}
\hline Time & GC & GV & $P$-value \\
\hline Basal & $87.00 \mathrm{~b} \pm 12.23$ & $87.71 \mathrm{~b} \pm 5.38$ & $P=0.89$ \\
1 & $100.20 \mathrm{a} \pm 6.98$ & $85.80 \mathrm{~b} \pm 9.34$ & $P=0.02$ \\
6 & $99.71 \mathrm{a} \pm 5.56$ & $99.00 \mathrm{a} \pm 4.43$ & $P=0.79$ \\
12 & $94.29 \mathrm{a} \pm 8.54$ & $97.14 \mathrm{a} \pm 7.90$ & $P=0.52$ \\
24 & $90.71 \mathrm{~b} \pm 11.18$ & $91.86 \mathrm{~b} \pm 9.65$ & $P=0.84$ \\
48 & $87.00 \mathrm{~b} \pm 13.00$ & $90.86 \mathrm{~b} \pm 6.94$ & $P=0.50$ \\
72 & $81.57 \mathrm{~b} \pm 4.69$ & $85.71 \mathrm{~b} \pm 14.49$ & $P=0.48$ \\
\hline$P$-value & $P=0.00$ & $P=0.04$ & \\
\hline
\end{tabular}

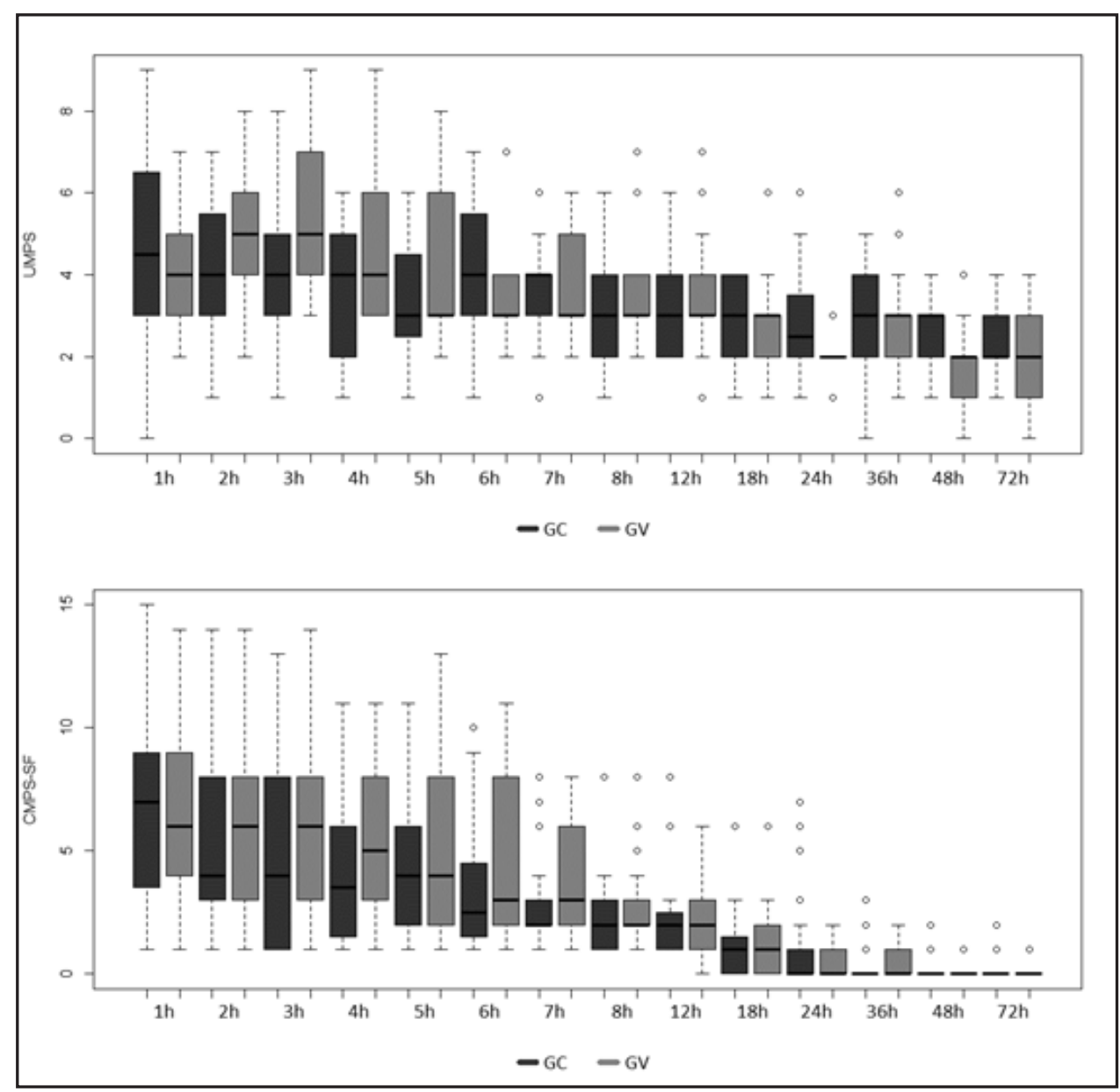

Figure 1. Median, first and third quartiles of the total points average of bitches underwent to two-port laparoscopicassisted (GV) or conventional (GC) OVH, in different time points, using the University of Melbourne (UMPS) and the Short-Form of the Glasgow Composite Measure (CMPS-SF) pain scales.

\section{DISCUSSION}

Hundreds of thousands animals are presented to US veterinarians annually for surgery or for evaluation of painful conditions. There is growing interest by veterinary clinical to explore the nature of animal acute and chronic pain syndromes and how best to treat it [10]; this is a world-concern in veterinary fields. The main pharmacological groups used to manage acute pain are the opioids and the non-opioid drugs, including NSAIDs and antipyretics drugs [11], 
as metamizol and scopolamine were selected in our research.

This study was conducted in order to elucidate the efficacy of metamizol and scopolamine to control pain after two modalities of $\mathrm{OVH}$ in dogs. A study evaluated different doses of metamizol applied 8-8 $\mathrm{h}$ and verified that 25 and $35 \mathrm{mg} \cdot \mathrm{kg}^{-1}$ provided better analgesia than smaller doses, but $20 \%$ of the animals of these study needed analgesic rescue [11]. Another study verified the combination of metamizol (25 mg.kg-1) and scopolamine (0.2 mg. $\left.\mathrm{kg}^{-1}\right)$ 8-8 h was not efficient to control pain after conventional and two port video-assisted OVH in dog female [18]. Considering these data, our study proposed to study the efficacy of metamizol $\left(25 \mathrm{mg} \cdot \mathrm{kg}^{-1}\right)$ and scopolamine $\left(0.2 \mathrm{mg} . \mathrm{kg}^{-1}\right)$ in 6-6 $\mathrm{h}$ regimen to dog female underwent to conventional and video-assisted $\mathrm{OVH}$.

It is difficult to recognize and quantify pain in dogs due to inter-individual variability in pain expression $[10,13]$. The recognition of pain relies on the interpretation of animal's behavior by an observer, because there is no effective means of communication between them [17]. It is accepted that pain assessment is better performed when multidimensional or composite scales are used [13,21]. For this reason, we used the UMPS and CMPS-SF scales, since they attended the statements proposed.

The UMPS consists of six categories (physiological data, response to palpation, activity, mental status, posture, and vocalization), each of which is divided into 3 or more levels and assigned a different numerical weight. At six categories, the patient is evaluated for each parameter by punctuation from zero (without pain) until three (highest pain). Twentyseven points is considered the most painful condition for this scale [10].

According to the UMPS, pain scores decreased at $8 \mathrm{hr}$ at GC. At GV the reduction was observed at 5,12 and $24 \mathrm{~h}$. At $36 \mathrm{~h}$ the average increased in GV and decreased again after $48 \mathrm{~h}$. The authors associated that the increasing happened because one animal of this group had dermatitis after shaver, what can cause alteration at pain.

Difference between groups were observed at 3 $\mathrm{h}$, with larger total points average in GV (5.0) than GC (4.0); at $48 \mathrm{~h}$ was observed major median and range of pain scores at GC (3.0) than GV (2.0). However, both findings did not show clinical importance. The biggest average points using UMPS in our study was 4.5 (T1) to GC and 5.0 (T2, T3) to GV, that suggests a good analgesic effect. Stands out, rescue is indicated when $30 \%$ of total punctuation is achieved, that could be necessary if nine points were achieved, that not happened in no animal of this study.

CMPS-SF is the unique composite scale designed using psychometric principles, which are well established in human medicine for the measurement of complex and intangible constructs such as intelligence, pain and quality of life [17]. At CG, higher punctuation (7.0) was observed at $1 \mathrm{~h}$ and decreased at 2, 3, 8 and finally at $18 \mathrm{~h}$. Animals of GV presented higher punctuation at 1 to $3 \mathrm{~h}(6.0)$, and decreasing points average at 5, 8 and $18 \mathrm{~h}$. No difference between groups was observed.

After surgery, glucose concentrations suffer elevation from the baseline and come to baseline after $24 \mathrm{~h}$ already described [3]. Authors suggest the metabolic response could be studied by serum glucose. The magnitude of this response is thought to be attributed to the perception of pain, according to the magnitude of surgical trauma. At GC the value increased at $1 \mathrm{~h}$, earlier than $\mathrm{GV}$ that happened at 6 $\mathrm{h}$ as cited [3]. Referred authors cited that maximum values happened from 4 to $6 \mathrm{~h}$, different as observed in our study. Although, considering glucoses related to pain, it could suggest there is differences between groups $1 \mathrm{~h}$ after surgery, with higher average to GC than GV $(P=0.02)$, (Figure 1), as suggested by authors [8], that laparoscopic approaches results in less stress than traditional procedures, although expend more time than open, as observed in our study.

The time to first spontaneous food intake was earlier in the GV $(5.57 \pm 3.21 \mathrm{~h})$ than $\mathrm{GC}(\mathrm{GC}=16.75$ $\pm 10.79 \mathrm{~h}, P=0.02$ ). It is recognized that animals submitted to video surgery experiences less abdominal discomfort than the animals undergoing open surgery [8], what could explain these results. Concerning to the time to first defecation, there was no different between groups $(\mathrm{GV}=17.60 \pm 9.21 \mathrm{~h}, \mathrm{GC}=31.71 \pm$ 17.90 h, $P=0.11)$.

Three animals of GC had postoperative emesis and episodes happened at $3 \mathrm{~h} ; 36$ and $48 \mathrm{~h}$, and $60 \mathrm{~h}$. Owners reported no changes following hospital discharge. Whilst not common, vomiting may occur in the first $6 \mathrm{~h}$ postoperatively in animals undergone isoflurane anesthesia [11], as observed in one patient. 
Although there have been sparse episodes, all of them happened at GC. It is suggested that metamizol, a weak NSAID whose mechanism may be the inhibition of COX-3 [11], could cause vomiting, but according to this, it was expected vomiting in both group, what not happened. On the other hand, notwithstanding the scales evaluation not suggested pain, other authors cited nausea, vomiting, diarrhea and abdominal distention as a clinical sign of abdominal pain [11], what could explain the observed result.

Differences between groups concerning to glucoses measurement, food intake and vomiting could be explained by superiority of the video surgery in comparison to open procedures [8]. Authors reported that laparoscopic approaches are clinically well accepted as being less painful and resulting in less stress than open procedures.

The efficacy of an analgesic can be measured by evaluating the number of animals needing rescue medication, pain scores [21] and objective parameters such as catecholamines and cortisol concentrations [8]. In our study none animal required additional postoperative analgesia at any time after surgery, i.e., major than nine points of a possible 27 at UMPS [10] and major of eight of a possible 24 at CMPS-SF [17,21], and the animals undergone to laparoscopic presented early food intake, smaller glucose levels and vomiting than those underwent to conventional.

Pain that occurs after an open procedure is also attributed to desiccation of exposed viscera and disruption of the peritoneal surface. Less pain associated with video surgery compared to open surgery is also attributed to the relatively less traumatic nature of bipolar cauterization and transection of the ovarian pedicle, compared with digital disruption of the suspensory ligament [4]. Controlled studies have evaluated pain after laparoscopic versus open sterilization and have demonstrated significant reduction in pain with video surgery $[8,15]$. In our study, no striking differences were observed between groups and different times. Authors believe that analgesic protocol was efficient to control pain, and it suppressed biggest difference between them.

The pain origin after the laparoscopic procedures is predominantly visceral than parietal. Also, pain from the thoracic region is frequent in human, secondary to the diaphragm irritation that could delay the patient recovering. The factors that could affect post operatory pain after video surgery is the duration of the procedure, the degree of abdominal pressure and the sub diaphragmatic gas volume after surgery [5].

\section{CONCLUSIONS}

The analgesic protocol was effective to control the pain after conventional or two-port laparoscopicassisted OVH in healthy dog female.

\section{MANUFACTURERS}

${ }^{1}$ Novartis Biociências SA. São Paulo, SP, Brazil.

${ }^{2}$ Vetnil Indústria e Comércio de Produtos Veterinários Ltda. Louveira, SP, Brazil.

${ }^{3}$ Fresenius-Kabi Brasil Ltda. Barueri, SP, Brazil.

${ }^{4}$ Cristália Produtos Químicos Farmacêuticos Ltda. Itapira, SP, Brazil. ${ }^{5}$ Lina Medical ApS. Glostrup, Denmark.

${ }^{6}$ Hipolabor Farmacêutica Ltda. Belo Horizonte, MG, Brazil.

Acknowledgements. The authors thanks to WEM Equipamentos Eletrônicos Ltda. (Ribeirão Preto, Brazil) and Lina Medical Inc. (Denmark) to provide the Lina Tripol Powerblade $5 \mathrm{~mm}$ diameter, $42 \mathrm{~cm}$ length laparoscopic bipolar forceps used to the laparoscopic-assisted OVH.

Ethical approval. Institutional review board approval of animal housing and experimental protocols was expedited by the Comitê de Ética no Uso de Animais (CEUA) of the University were the study was developed (Protocol 081/2012).

Declaration of interest. The authors report no conflicts of interest. The authors alone are responsible for the content and writing of the paper.

\section{REFERENCES}

1 Brun M.V. 2015. Cirurgias do aparelho reprodutor feminino de caninos. In: Brun M.V. (Ed). Videocirurgia em Pequenos Animais. Rio de Janeiro: Roca, pp.186-283.

2 Chandrasekharan N.V., Dai H., Roos K.L.T., Evanson N.K., Tomsik J., Elton T.S. \& Simmons D.L. 2002. Cox-3, a cyclooxygenase-1 variant inhibited by acetaminophen and other analgesic/antipyretic drugs: cloning, structure and expression. Proceedings of the National Academy of Sciences of the United States of America. 99(21): 13926-13931.

3 Desborough J.P. 2000. The stress response to trauma and surgery. British Journal of Anaesthesia. 85(1): 109-117. 
4 Devitt C.M., Cox R.E. \& Hailey J.J. 2005. Duration, complications, stress, and pain of open ovariohysterectomy versus a simple method of laparoscopic-assisted ovariohysterectomy in dogs. Journal of the American Veterinary Medical Association. 227(6): 921-927.

5 Duque C.T.N. \& Moreno J.C.D. 2015. Anestesia e Analgesia Para Videocirurgia. In: Brun M.V. (Ed). Videocirurgia em Pequenos Animais. Rio de Janeiro: Roca, pp.7-20.

6 Derry S., Faura C., Edwards J., McQuay H.J. \& Moore R.A. 2010. Single dose dipyrone for acute postoperative pain. Cochrane Database of Systematic Reviews 2010. 9: CD003227

7 Fox S.M., Mellor D.J., Stafford K.J., Lowoko C.R. \& Hodge H. 2000. The effects of ovariohysterectomy plus different combinations of halothane anaesthesia and butorphanol analgesia on behavior in the bitch. Research in Veterinary Science. 68(3): 264-274.

8 Freeman L.J., Rahmani E.Y., Al-Haddad M., Sherman S., Chiorean M.V., Selzer D.J., Snyder P.W. \& Constable P.D. 2010. Comparison of pain and postoperative stress in dogs undergoing natural orifice transluminal endoscopic surgery, laparoscopic, and open oophorectomy. Gastrointestinal Endoscopy. 72(2): 373-380.

9 Ganem E.M., Salem I.C.F. \& Fukushima F.B. 2005. Eficácia da N-butilescopolamina e dipirona sódica associadas ao cetoprofeno no alívio da dor pós-operatória de pacientes submetidas a duas técnicas diferentes de laqueadura por laparoscopia. Revista Brasileira de Anestesiologia. 55(4): 397-404.

10 Hansen B.D. 2003. Assessment of Pain in Dogs: Veterinary Clinical Studies. Institute for Laboratory Animal Research Journal. 44(3): 197-205.

11 Imagawa H.V., Fantoni D.T., Tatarunas A.C., Mastrocinque S., Almeida T.F., Ferreira F. \& Posso I.P. 2011. The use of different doses of metamizol for post-operative analgesia in dogs. Veterinary Anaesthesia and Analgesia. 38(4): 385-393.

12 Joshi G.P. 2002. Anesthesia for laparoscopic surgery. Canadian Journal of Anesthesia. 49(1): R45-R49.

13 Kim Y.K., Lee S.S., Suh E.H., Lee L., Lee H.C, Lee H.J. \& Yeon S.C. 2012. Sprayed intraperitoneal bupivacaine reduces early postoperative pain behavior and biochemical stress response after laparoscopic ovariohysterectomy in dogs. The Veterinary Journal. 191(2): 188-192.

14 Levy M., Zylber-Katz E. \& Rosenkranz B. 1995. Clinical pharmacokinetics of dipyrone and its metabolites. Clinical Pharmacokinetics. 28(3): 216-234.

15 Mama K. \& Rezende M.L. 2015. Anesthesia management of dogs and cats for laparoscopy. In: Frasson B.A. \& Mayhew P.D. (Eds). Small Animal Laparoscopy and Thoracoscopy. Ames: Wiley-Blackwell, pp.75-80.

16 Macphail M. C. \& Fossum T.W. 2019. Surgery of the reproductive and genital systems. In: Fossum T.W. (Ed). Small Animal Surgery. Philadelphia: Elsevier, pp.720-787.

17 Murrell J.C., Psatha E.P., Scott E.M., Reid J. \& Hellebrekers L.J. 2008. Application of a modified form of the Glasgow pain scale in a veterinary teaching centre in the Netherlands. Veterinary Record. 162(13): 403-408.

18 Oliveira M.T. 2013. Analgesia da dipirona e escopolamina pós ovário-histerectomia convencional ou videoassistida em cadelas. 40f. Santa Maria, RS. Dissertação (Mestrado em Medicina Veterinária) - Programa de Pós-Graduação em Medicina Veterinária, Universidade Federal de Santa Maria.

19 R Core Team. 2019. R: A language and environment for statistical computing. Vienna: R Foundation for Statistical Computing. (Vienna, Austria). http://www.r-project.org/index.html

20 Santos C. 2018. Distribuições bidimensionais. In: Estatística Descritiva: Manual de Auto-aprendizagem. 3.ed. Lisboa: Edições Sílabo, pp.125-156.

21 Wiese A.J. 2014. Assessing pain. In: Gaynor J. \& Muir W. (Eds). Handbook of Veterinary Pain Management. Saint Louis: Elsevier Mosby, pp.67-96. 